\title{
Study and Application of a Novel Tap Water Flocculant
}

\author{
Defang Zeng ${ }^{1}$, Yong Zhai ${ }^{1}$, Shuisheng Zhang ${ }^{2}$, Fujun Ding ${ }^{2}$ \\ ${ }^{1}$ School of Resource and Environmental Engineering, Wuhan University of Technology, Hubei Key Lab of Mineral Resource Proc- \\ essing and Environment, Wuhan, China; ${ }^{2}$ Hubei Shilu Chemical Coat Company, Yingcheng, China. \\ Email: zhaiyong2005@126.com
}

Received February $23^{\text {rd }}, 2012$; revised March $25^{\text {th }}, 2012$; accepted April $19^{\text {th }}, 2012$

\begin{abstract}
By using polyaluminum chloride (PAC), chitosan (CTS) and montmorillonite (MM) as the main raw materials, a novel tap water flocculant had been prepared. The optimal mass proportion of this flocculant was $1 \mathrm{~g} \cdot \mathrm{L}^{-1}$ chitosan:50 $\mathrm{g} \cdot \mathrm{L}^{-1}$ PAC: $3 \mathrm{~g} \cdot \mathrm{L}^{-1} \mathrm{MM}=30: 11: 7$. Compared with the traditional polyaluminum chloride (PAC), the concentration of aluminum ion $\left(\mathrm{Al}^{3+}\right)$ and suspended solids (SS) in the exit dropped $66.19 \%$ and $5.80 \%$ respectively, moreover, the cost was decreased by $9.95 \%$. This flocculant was not only cheaper, but also provided improved flocculating function compared with traditional flocculant. The concentration of $\mathrm{Al}^{3+}$ in exit water was decreased greatly so the drinking water would be much safer.
\end{abstract}

Keywords: Water Treatment; Composite Flocculant; Flocculant; Aluminum Ion

\section{Introduction}

Currently the polyaluminum chloride (PAC) has been widely used in tap water treatment $[1,2]$. With the application of this chemical, it is generally inevitable to produce secondary pollution resulted from $\mathrm{Al}^{3+}[3]$, which brings threats and harms to human health [4]. Thus, there is a demand for an eco-friendly alternative to ensure treatment effect and human health.

In the study, a novel tap water flocculant was discovered based on lower concentration of $\mathrm{Al}^{3+}$ in exit water. The novel flocculant was made by polyaluminum chloride (PAC), Chitosan (CTS), and montmorillonite (MM). Owing to the decreased dosage of PAC, the concentration of $\mathrm{Al}^{3+}$ in exit water was significantly reduced. Besides, a large number of amino $\left(\mathrm{NH}_{2}\right)$ and hydroxyl $(\mathrm{OH})$ groups on the molecular chain of CTS could form stable cheated compounds with $\mathrm{Al}^{3+}$ so as to remove part of metal ions from water. MM mainly play an adsorption role in tap water treatment to reduce the SS in exit water.

\section{Experiments}

\subsection{Main Apparatus}

Magnetism msier (78-1, Ronghua Equipment Manufacture Co., Ltd, Jiangsu, China); Scattering-type optoelectronic SSmeter (WGZ-100, Jinziguang Apparatus Company, Beijing, China); Digital electronic scale (BA210, Ohaus, Berlin, Germany) accurate to $0.0001 \mathrm{~g}$; Electrical inductive coupling plasma mass spectrometer (ELAN6000,
Sigma, Boston, USA); High-speed disperser (GFJO4A, Coating Industry Factory, Shanghai, China); Digital PH meter (pHS-25, Lida Apparatus Company, Shanghai, China); Air dry oven (FN101-3A, Apparatus Company, Changsha, China); Quartz automatic triple water distiller (1810-C, Kanghua Electronic Apparatus Factory, Jiangsu, China).

\subsection{Main Reagents}

Chitosan (CTS) with a viscosity of about $30-3000 \mathrm{mPa} \cdot \mathrm{S}$ at 25 degrees Celsius and a degree of deacetylation of about $85 \%$ - 98\%; Poly (aluminum chloride) with an $\mathrm{Al}_{2} \mathrm{O}_{3}$ content of more than $32 \%$; Polymerized ferrous sulfate (PFS) with an Fe content of more than 22\%; Natural montmorillonite (MM) with its content more than $70 \%$, fineness less than $0.043 \mu \mathrm{m}$ and specific surface of $260 \mathrm{~m}^{2} \cdot \mathrm{g}^{-1}$; Cationic polyacrylamide (CPAM) with molecular weight of about $3-15$ million and degree of cationic of about $5 \%-80 \%$; Acetic acid with an HAc content of more than $99 \%$.

\subsection{Raw Water}

The raw water was obtained from The Yangtze River of Wuhan in China (SSvalue $=85.6$ NTU, water temperature of about $21-25$ degrees Celsius, $\mathrm{pH}=7.2$ ).

\subsection{Preparation of the Composite Flocculant}

There were 5 steps in the process of single-component 
flocculant preparation: 1) CTS was first dissolved in acetic acid. This formed suspension was diluted with water and stirred for $3.5 \mathrm{~h}$ at 25 degrees Celsius to prepare CTS working solution of $50 \mathrm{mg} \cdot \mathrm{L}^{-1}$. 2) Similarly PAC was mixed with water to form working solution of $1 \mathrm{~g} \cdot \mathrm{L}^{-1}$. It took about $5 \mathrm{~min}$ to dissolve completely under stirring at 25 degrees Celsius. 3) MM was mixed with water to form working solution of $3 \mathrm{~g} \cdot \mathrm{L}^{-1}$. It took about $6 \mathrm{~h}$ under stirring at 25 degrees Celsius. 4) CPAM was diluted with water and oscillated for $4 \mathrm{~h}$ at 25 degrees Celsius to form CPAM solution of $1 \mathrm{~g} \cdot \mathrm{L}^{-1}$. 5) PFS was mixed with water and stirred for $5 \mathrm{~min}$ at 25 degrees Celsius to prepare PFS solution of $1 \mathrm{~g} \cdot \mathrm{L}^{-1}$.

\subsection{Experimental Methods}

Eight samples of $200 \mathrm{~mL}$ raw water were placed into eight $250 \mathrm{~mL}$ beakers, and various different categories and dosages of flocculants were added under stirring. The solution was quickly stirred for $4 \mathrm{~min}$ at a speed of $260 \mathrm{r} \cdot \mathrm{min}^{-1}$ and then slowly stirred for $8 \mathrm{~min}$ at the speed of $65 \mathrm{r} \cdot \mathrm{min}^{-1}$. The liquid was transferred to a separating funnel, where the floc was allowed to settle for $30 \mathrm{~min}$. A small volume of the upper layer was removed from the funnel, and the concentration of $\mathrm{Al}^{3+}$ and turbidity in exit water in this liquid were measured. In this way, a set of data were obtained.

The liquid was stirred by magnetism msier. The turbidity in exit water was measured by Scattering-type optoelectronic turbidity meter. The concentration of $\mathrm{Al}^{3+}$ was measured by electrical inductive coupling plasma mass spectrometer.

\section{Results and Discussion}

\subsection{Confirming the Optimal Prescription}

Based on reaching lower cost than that of traditional flocculant, three single-component flocculant were selected as a group and mixed in the proportion of $1: 1: 1$. Eight specimens were designed and tested to determine the optimal prescription in terms of lower cost and better removal rate of $\mathrm{SS}$.

Taking the higher accuracy and lower cost into account, we used $0.1 \mathrm{~mL}$ as the volume unit. The flocculant category and experimental data could be seen in Table 1.

The SS of 8 treatments in exit water was all higher than 16 NTU (Table 1). The treatment effect of the composite flocculant which contained CPAM was not satisfactory. The specimens containing both CPAM and MM were worse than other specimens. On the whole, the specimen 4 had the best effect and it was the optimal combination to be used. Its turbidity in exit water was only 16.2 NUT and removal rate of SS reached $81.07 \%$. So the optimal prescription was made by $1 \mathrm{~g} \cdot \mathrm{L}^{-1} \mathrm{PAC}$,
$50 \mathrm{mg} \cdot \mathrm{L}^{-1} \mathrm{CTS}$, and $3 \mathrm{~g} \cdot \mathrm{L}^{-1} \mathrm{MM}$.

\subsection{Confirming the Optimum Dosage}

The optimum dosage of single-component flocculant was determined based on lower cost and better treatment effect. Thus this flocculant was superior to traditional one for the improved performance-price ratio and strong market competitiveness.

\subsubsection{Confirming the Optimum Dosage of PAC} With the content of CTS and MM maintaining to $0.1 \mathrm{~mL}$, the dosage of PAC was gradually changed in order to determine its optimum dosage.

Figure 1 showed that the larger the dosage of PAC; the lower the turbidity in exit water. When the dosage of PAC was less than $0.6 \mathrm{~mL}$, with the dosage of PAC increasing, the turbidity in exit water was significantly decreased. When the dosage of PAC was more than $0.6 \mathrm{~mL}$, the treatment effect of tap water was not very satisfactory with the dosage of PAC increasing. When the dosage of PAC was $1.0 \mathrm{~mL}$, the turbidity in exit water was 3.12 NTU and the removal rate of SS was $96.3 \%$. However, the cost of composite flocculant was higher than that of traditional flocculant.

Figure 1 showed that the larger dosage of PAC was added, the higher concentration of $\mathrm{Al}^{3+}$ was in exit water.

Table 1. The treatment results of 8 specimens.

\begin{tabular}{cccc}
\hline NO. & $\begin{array}{c}\text { Flocculant category } \\
(1: 1: 1)\end{array}$ & $\begin{array}{c}\text { Turbidity in exit water } \\
(\text { NTU) }\end{array}$ & $\begin{array}{c}\text { Removal rate of SS } \\
(\%)\end{array}$ \\
\hline 1 & PAC + CPAM + CTS & 21.5 & 74.88 \\
2 & PAC + CPAM + MM & 22.7 & 73.48 \\
3 & PAC + PFS + CTS & 18.3 & 78.62 \\
4 & PAC + CTS + MM & 16.2 & 81.07 \\
5 & PFS + CPAM + MM & 23.9 & 72.08 \\
6 & PFS + PAC + MM & 20.1 & 76.52 \\
7 & PFS + PAC + CTS & 20.4 & 76.17 \\
8 & PFS + CPAM + CTS & 18.1 & 78.86 \\
\hline
\end{tabular}

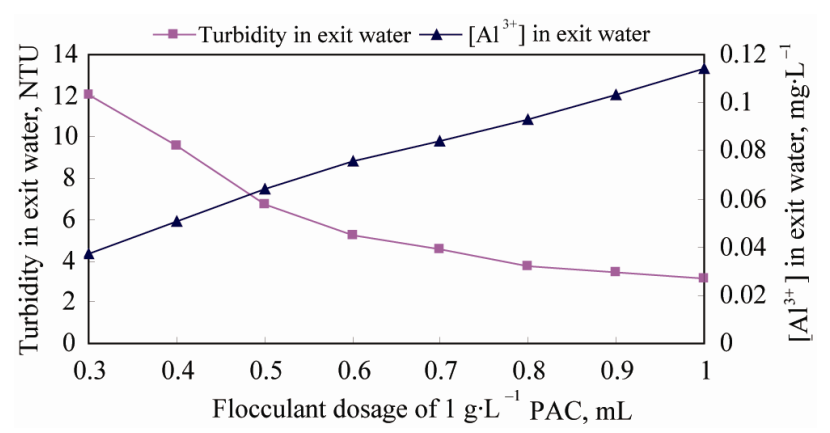

Figure 1. Relationship between dosage of PAC and turbidity, $\left[\mathrm{Al}^{3+}\right]$ in exit water. 
So the optimum dosage of PAC was $0.6 \mathrm{~mL}$. The cost of composite flocculant and concentration of $\mathrm{Al}^{3+}$ in exit water was decreased; what's more, the tap water treatment effect was better than that of traditional flocculant.

\subsubsection{Confirming the Optimum Dosage of CTS}

In a similar way, the dosage of PAC and MM was maintained to $0.6 \mathrm{~mL}$ and $0.1 \mathrm{~mL}$ respectively. The dosage of CTS was gradually changed in order to find the optimum dosage.

Figure 2 showed that with the dosage of CTS increasing, the turbidity in exit water was decreased at the beginning and then increased suddenly. If the dosage of CTS was very large, the treatment effect of tap water was not very satisfactory. When the dosage of CTS reached $0.22 \mathrm{~mL}$, the turbidity in exit water was $1.28 \mathrm{NTU}$ and the concentration of $\mathrm{Al}^{3+}$ was $0.065 \mathrm{mg} \cdot \mathrm{L}^{-1}$, showing the best treatment effect of tap water. So the optimum dosage of CTS was $0.22 \mathrm{~mL}$.

\subsubsection{Confirming the Optimum Dosage of MM}

Similarly, the dosage of PAC and CTS was maintained to $0.6 \mathrm{~mL}$ and $0.1 \mathrm{~mL}$ respectively. The dosage of MM was gradually changed in order to determine the optimum dosage.

Figure 3 showed that when the dosage of MM was lower than $0.14 \mathrm{~mL}$, with the dosage of MM increasing, the turbidity in exit water was significantly decreased.

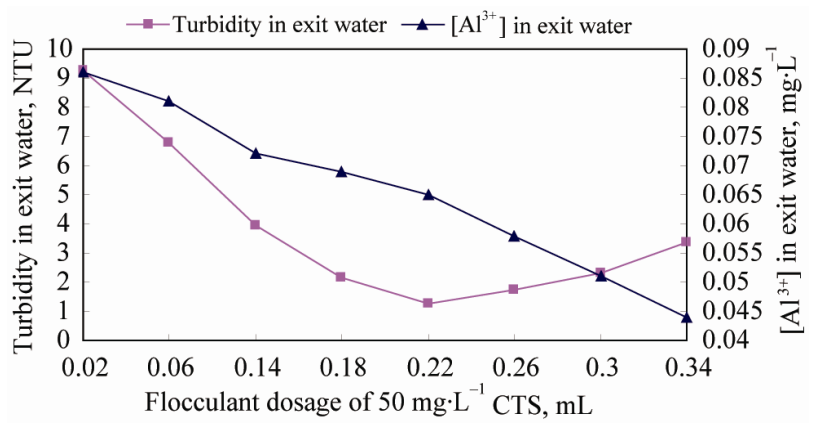

Figure 2. Relationship between dosage of CTS and turbidity, $\left[\mathrm{Al}^{3+}\right]$ in exit water.

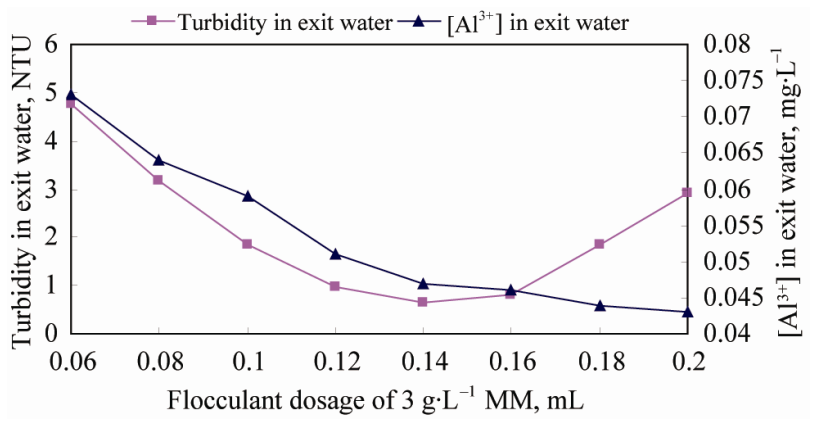

Figure 3. Relationship between dosage of MM and turbidity, $\left[\mathrm{Al}^{3+}\right]$ in exit water.
However, when the dosage of MM was higher than 0.14 $\mathrm{mL}$, the turbidity in exit water was significantly increased. This is because the MM suspension was a kind of emulsion which had a negative influence on the transparency of exit water. When the dosage of MM was $0.14 \mathrm{~mL}$, the turbidity in exit water was only 0.65 NTU and the concentration of $\mathrm{Al}^{3+}$ was $0.057 \mathrm{mg} \cdot \mathrm{L}^{-1}$. So the optimum dosage of MM was $0.14 \mathrm{~mL}$.

In conclusion, the novel composite flocculant was prepared in the weight proportions: $1 \mathrm{~g} \cdot \mathrm{L}^{-1} \mathrm{PAC}: 50 \mathrm{mg} \cdot \mathrm{L}^{-1}$ CTS:3 $\mathrm{g} \cdot \mathrm{L}^{-1} \mathrm{MM}=30: 11: 7$. The removal rate of $\mathrm{SS}$ reached $99.24 \%$. The reasons were as follows: The concentration of $\mathrm{Al}^{3+}$ was decreased by using less dosage of PAC, at the same time, the CTS and MM played the role of flocculation and adsorption.

\subsection{Confirming the Optimum Reaction Conditions}

\subsubsection{Confirming the Optimum Reaction Temperature}

When the PH value was 7 and other conditions were confirmed, we conducted the tests to determine the optimal reaction temperature of composite flocculant (Figure 4).

The results of the experiment showed that the removal rate of SS was enhanced when the reaction temperature in the range from $0^{\circ} \mathrm{C}$ to $30^{\circ} \mathrm{C}$, and then decreased when the temperature was higher than $30^{\circ} \mathrm{C}$. The $\mathrm{Al}^{3+}$ in exit water was decreased when the reaction temperature in the range from $0^{\circ} \mathrm{C}$ to $40^{\circ} \mathrm{C}$, and then enhanced when the temperature was higher. It showed that when the temperature was from $10^{\circ} \mathrm{C}$ to $40^{\circ} \mathrm{C}$, the flocculation effect was very good.

\subsubsection{Confirming the Optimum Reaction pH Value}

When the water temperature was $30^{\circ} \mathrm{C}$ and other conditions were confirmed, a series of tests were conducted to study the flocculation effectiveness of composite flocculant under various $\mathrm{pH}$ value conditions.

Figure 5 showed that the optimal flocculation effect of composite flocculant at $\mathrm{pH}$ value 7 . When the $\mathrm{pH}$ was higher than 7, the removal rate of SS was slightly in-

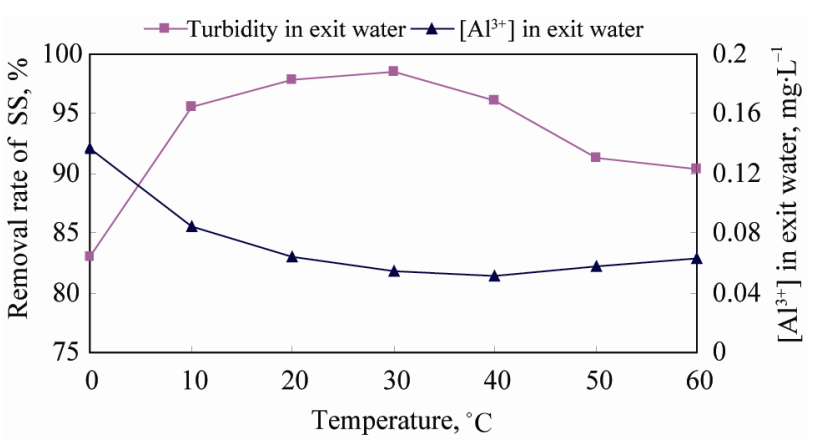

Figure 4. Influence of temperature on flocculation effect. 
creased and $\mathrm{Al}^{3+}$ in exit water was slightly decreased. As the $\mathrm{pH}$ of raw water is 7 , from the aspects of low cost and high efficiency, 7 is the optimal $\mathrm{pH}$.

\subsection{The Treatment Results of Traditional Flocculant (PAC)}

The tap water treatment results of traditional flocculant (PAC) were as follows.

Figure 6 showed that when the dosage of PAC was $1.3 \mathrm{~mL}$, the turbidity in exit water was $0.81 \mathrm{NTU}$ higher than that of composite flocculant. What's more, when the dosage of PAC was $1.4 \mathrm{~mL}$, the turbidity in exit water was higher than that of composite flocculant, and the cost of traditional flocculant was higher than that of composite one too. Figure 6 showed that whether the dosage of traditional flocculant (PAC) was $1.3 \mathrm{~mL}$ or $1.4 \mathrm{~mL}$, the concentration of $\mathrm{Al}^{3+}$ was both higher than that of composite flocculant. In conclusion, the performance-price ratio of composite flocculant was higher than that of traditional flocculant.

\subsection{Comparison between Composite and Traditional Flocculant (PAC)}

Comparing the novel composite flocculant to traditional flocculant, we could get the main economic indicators (Table 2).

Table 2 showed that the treatment effect of novel com-

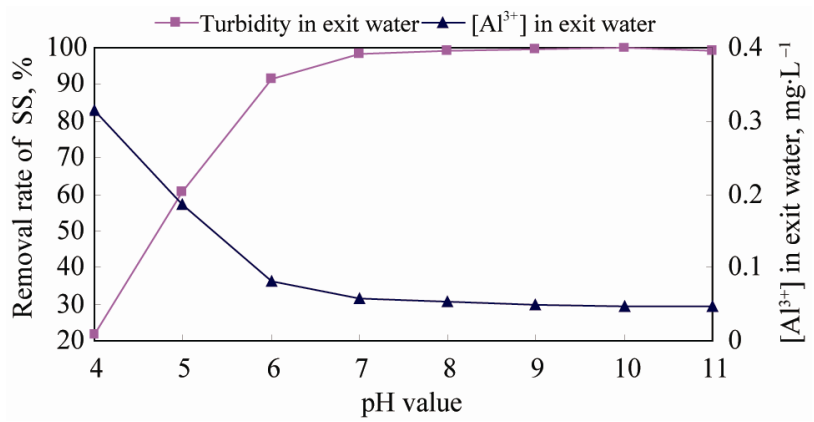

Figure 5. Influence of pH value on flocculation effect.

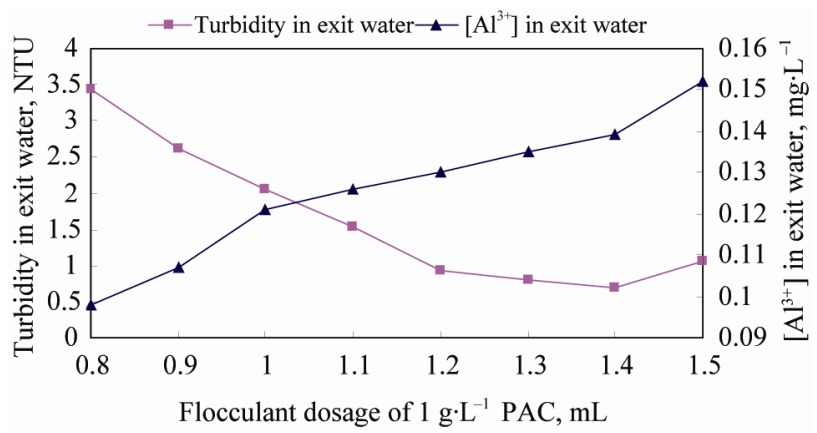

Figure 6. Relationship between dosage of traditional flocculant (PAC) and turbidity, $\left[\mathrm{Al}^{3+}\right]$ in exit water.
Table 2. The result of competition on main economic indicators.

\begin{tabular}{lcc}
\hline \multicolumn{1}{c}{ Category of flocculant } & $\begin{array}{c}\text { Traditional } \\
\text { flocculant (PAC) }\end{array}$ & $\begin{array}{c}\text { Novel composite } \\
\text { flocculant }\end{array}$ \\
\hline Turbidity in exit water (NTU) & 0.69 & 0.65 \\
Removal rate of SS (\%) & 99.15 & 99.24 \\
Decline rate of SS (\%) & & 5.80 \\
{$\left[\mathrm{Al}^{3+}\right]$ in exit water $\left(\mathrm{mg} \cdot \mathrm{L}^{-1}\right)$} & 0.139 & 0.047 \\
Decline rate of $\mathrm{Al}^{3+}(\%)$ & & 66.19 \\
\hline
\end{tabular}

posite flocculant was better than that of traditional flocculant. The concentration of $\mathrm{Al}^{3+}$ and $\mathrm{SS}$ in exit water was decreased by $66.19 \%$ and $5.80 \%$ respectively; moreover, the cost of this flocculant was decreased by $9.95 \%$. The composite flocculant could bring environmental and economic benefits greatly. The concentration of $\mathrm{Al}^{3+}$ in exit water was $0.047 \mathrm{mg} \cdot \mathrm{L}^{-1}$, and it was lower than 0.05 $\mathrm{mg} \cdot \mathrm{L}^{-1}$. With the application of this composite chitosan flocculant in tap water treatment, harms caused by aluminum ions to human and environment were greatly reduced, showing a significant market prospect in tap water treatment.

\subsection{The Mechanism of Flocculation Effect}

\subsubsection{PAC Plays the Role of Neutralization, Adsorption and Bridge}

PAC can make a more stable rearrangement structure on the surface of the colloidal solid after dissolution [5]. PAC with high quantity of electric charge is able to significantly increase the power of neutralization [6]. The groups of $\mathrm{OH}$ can link the flocs and metal ions together and form bigger floc particles [7].

\subsubsection{CTS Play the Role of Bridge, Neutralization and Chelation [8]}

A large number of amino $\left(\mathrm{NH}_{2}\right)$ and hydroxyl $(\mathrm{OH})$ groups on the molecular chain of CTS carry non-bonded pairs of electrons which can donate to empty d-orbital of metal ions and form stable chelated compounds [9]. So chitosan can be used to remove many deleterious metal ions from water [10], including $\mathrm{Al}^{3+}, \mathrm{Zn}^{2+}, \mathrm{Cr}^{3+}, \mathrm{Hg}^{2+}$, $\mathrm{Ag}^{+}, \mathrm{Pb}^{2+}, \mathrm{Ca}^{2+}, \mathrm{Cu}^{2+}$ and $\mathrm{Cd}^{2+}$. The active amino groups can also be protonated with $\mathrm{H}^{+}$in water to form a cationic polyelectrolyte. Because of this cationic polyelectrolyte's static attraction and adsorption, chitosan can make colloidal particles to sedimentation $[11,12]$.

\subsubsection{MM's Adsorption Is Very Strong}

The MM has a strong adsorption as the surface area and ion exchange capacity is enlarged through modification [13]. 


\subsubsection{The Complex of CTS, PAC and MM Has the Effect of Complementary and Synergy Advantages}

The neutralization effect of PAC and adsorption of MM can form a strong adsorption. The adsorption and bridge of CTS can flocculate particles into bigger floc that could settle out. The combination use of CTS and MM make destabilization of colloidal particles and improvement of coagulation velocities $[14,15]$.

\section{Conclusions}

Compared with traditional chemical flocculant (PAC), the novel composite flocculant had the following advantages: higher removal efficiency for SS and $\mathrm{Al}^{3+}$, lower material cost, easier treatment of tap water, and less pollution. Results showed that this flocculant with good properties played a positive role in tap water treatment. It was also observed that the novel composite flocculant was prepared in the weight proportions: $1 \mathrm{~g} \cdot \mathrm{L}^{-1}$ PAC:50 $\mathrm{mg} \cdot \mathrm{L}^{-1} \mathrm{CTS}: 3 \mathrm{~g} \cdot \mathrm{L}^{-1} \mathrm{MM}=30: 11: 7$.

PAC and CTS both have the effect of neutralization, bridge and adsorption. But PAC mainly plays a part in neutralization and adsorption, while CTS mainly has a role in bridge and flocculation. MM has a strong adsorption. In conclusion, the synergism in the three flocculants provides excellent flocculation effect in water treatment.

Compared with traditional chemical flocculant (PAC), the concentration of $\mathrm{Al}^{3+}$ and $\mathrm{SS}$ in exit water was decreased by $66.19 \%$ and $5.80 \%$ respectively; moreover, the cost of this flocculant was decreased by $9.95 \%$. Hence it is likely to gain wide acceptance and application for tap water treatment. There will be economic and environmental benefits on using this novel composite flocculant as an alternative to the traditional flocculant PAC in water treatment.

\section{Acknowledgements}

The authors are grateful to the technology office in Hubei Province in P. R. China who offered us the science and technology research fund. We also express our thanks to the ministry of science and technology in P. R. China who offered us the SME technology Innovation Fund.

\section{REFERENCES}

[1] M. Y. Liu, X. M. Hu, X. J. Zhang and Y. B. Su, "Polymeric Aluminum-Calcium Chloride: A New Flocculant and Its Preparation and Preliminary Application," Journal of Northeastern University, Vol. 26, No. 5, 2005, pp. 500503.

[2] P. T. Srinivasan, T. Viraraghavan, B. Kardash and J. Bergman, "Aluminum Speciation during Drinking Water
Treatment," Water Quality Research Journal of Canada, Vol. 33, No. 3, 1998, pp. 377-388.

[3] M. I. Sadawi and R. H. Ismail, "Factors Affecting the Residual Aluminum in Potable Water and Quality Assurance," Journal of Engineering and Applied Science, Vol. 51, No. 3, 2004, pp. 447-462.

[4] R. D. Letterman and C. T. Driscoll, "Survey of Residual Aluminum in Filtered Water," American Water Works Association, Vol. 80, No. 4, 1988, pp. 154-158.

[5] S. Vigneswaran, D. S. Chaudhary, H. H. Ngo, W. G. Shim and H. Moon, "Application of A PAC-Membrane Hybrid System for Removal of Organics from Secondary Sewage Effluent: Experiments and Modeling," Separation Science and Technology, Vol. 38, No. 10, 2003, pp. 2183-2199. doi:10.1081/SS-120021619

[6] T. Maria, M. Sylwia and A. W. Morawski, "Removal of Organic Matter by Coagulation Enhanced with Adsorption on PAC," Desalination, Vol. 161, No. 1, 2004, pp. 79-87. doi:10.1016/S0011-9164(04)90042-2

[7] S. K. Dentel and J. M. Gossett, "Mechanisms of Coagulation with Aluminum Salts," American Water Works Association, Vol. 80, No. 4, 1988, pp. 187-198.

[8] D. Zeng, J. Wu and J. F. Kennedy, "Application of a Chitosan Flocculant to Water Treatment," Carbohydrate Polymers, Vol. 71, No. 1, 2008, pp. 135-139. doi:10.1016/j.carbpol.2007.07.039

[9] Q. W. Deng, J. W. Wang and L. V. Jinsong, "Adsorption of Cadmium by Magnetic Chitosan Microspheres," 2011 International Conference on Electrical and Control Engineering, Yichang, 16-18 September 2011, pp. 3335-3338.

[10] P. Miretzky and C. A. Fernandez, "Hg(II) Removal from Water by Chitosan and Chitosan Derivatives: A Review," Journal of Hazardous Materials, Vol. 167, No. 1-3, 2009, pp. 10-23. doi:10.1016/j.jhazmat.2009.01.060

[11] M. Zhang, C. Y. Tan, L. Kong and L. C. Jin, "Preparation of a Novel Chitosan Derivative and Use in Water Treatment," 2011 International Conference on Multimedia Technology, Hangzhou, 26-28 July 2011, pp. 1160-1162. doi:10.1109/ICMT.2011.6002962

[12] H. Yang, B. Yuan, Y. B. Lu and R. S. Cheng, "Preparation of Magnetic Chitosan Microspheres and Its Applications in Wastewater Treatment," Science in China, Series B: Chemistry, Vol. 52, No. 3, 2009, pp. 249-256. doi:10.1007/s11426-008-0109-1

[13] Y. L. Tang, J. C. Chen and D. F. Zeng, "Study on the Flocculation Mechanism of Modified Rectorite/Chitosan Composite Flocculant," Journal of Chemical Industry and Engineering, Vol. 28, No. 3, 2007, pp. 11-14.

[14] D. S. Wang and X. H. Tang, "Quantitative Model of Coagulation with Inorganic Polymer Flocculant PAC: Application of the PCNM," Journal of Environmental Engineering, Vol. 32, No. 5, 2006, pp. 434-441. doi:10.1061/(ASCE)0733-9372(2006)132:5(434)

[15] J. K. Edzwald, "Coagulation in Drinking Water Treatment: Particles, Organics and Coagulants," Water Science and Technology, Vol. 27, No. 11, 1993, pp. 21-35. 